\title{
AVALIAÇÃO DA QUALIDADE DE SOLOS SOB DIFERENTES COBERTURAS FLORESTAIS E DE PASTAGEM NO SUL DE MINAS GERAIS ${ }^{(1)}$
}

\author{
Rogério Melloni ${ }^{(2)}$, Eliane Guimarães Pereira Melloni ${ }^{(2)}$, Maria Inês \\ Nogueira Alvarenga ${ }^{(2)}$ \& Fernanda Bueno Marcondes Vieira ${ }^{(3)}$
}

\begin{abstract}
RESUMO
No sul de Minas Gerais faz-se a substituição de florestas de araucária por pastagens ou extensos plantios de eucalipto. No entanto, poucos estudos relacionam, de forma ampla, os impactos nos atributos físicos, químicos, microbianos e visuais do solo causados por esta substituição. Com esse objetivo, selecionaram-se áreas com eucalipto, araucária implantada, mata nativa e pasto implantado em Delfim Moreira, MG, no verão de 2006, de onde se retiraram amostras deformadas e indeformadas de solo para análises químicas (pH, $\mathrm{P}, \mathrm{K}, \mathrm{Ca}^{2+}, \mathrm{Mg}^{2+}, \mathrm{Al}^{3+}, \mathrm{H}+\mathrm{Al}, \mathrm{SB}$, t, T, V, m e matéria orgânica), físicas (densidade do solo, densidade de partículas, índice de floculação, diâmetro médio geométrico, macro e microporosidade) e microbianas (atividade microbiana, $q \mathrm{CO}_{2}, \mathrm{C}$ da biomassa microbiana, relação $\mathrm{C}$ da biomassa/C orgânico). Com atributos visuais ligados ao solo, às plantas e aos animais, elaborou-se um indicador da qualidade visual para cada ecossistema, que se destacou pela praticidade, simplicidade e sensibilidade na discriminação das diferentes coberturas vegetais. A grande maioria dos atributos físicos e microbianos mostrou-se eficiente nas avaliações da qualidade ambiental, que revelaram grande disparidade entre a pastagem e os demais ecossistemas, e alta similaridade entre o ecossistema eucalipto com sub-bosque desenvolvido e araucária implantada.
\end{abstract}

Termos de indexação: araucária, eucalipto, indicadores da qualidade do solo.

\footnotetext{
(1) Projeto vinculado ao Grupo de Pesquisa "Solos e Meio Ambiente - SOMA", do CNPq. Recebido para publicação em fevereiro de 2008 e aprovado em setembro 2008.

(2) Professor Adjunto do Instituto de Recursos Naturais, Universidade Federal de Itajubá - UNIFEI. Av. BPS, 1303, Pinheirinho, Caixa Postal 50, CEP 37500-903 Itajubá (MG).E-mails: rmelloni@unifei.edu.br; elianegp@unifei.edu.br; mariaines@unifei.edu.br

(3) Engenheira Ambiental, UNIFEI. E-mail: fernandabmv@yahoo.com.br
} 


\title{
SUMMARY: EVALUATION OF SOIL QUALITY UNDER DIFFERENT FOREST COVERS AND PASTURE IN SOUTHERNMINAS GERAIS STATE, BRAZIL
}

\begin{abstract}
Native forests have frequently been substituted by Eucalyptus or annual crops cultivation in Brazil. In southern Minas Gerais State the substitution of Araucaria angustifolia forests by agricultural systems or extensive Eucalyptus stands has also been observed. However, few studies are focused on the impacts of such land use changes on soil physical, chemical and microbial and visual aspect of soils. With this goal in mind, different ecosystems were selected, including introduced Eucalyptus and Araucaria and native forest and pasture in Delfim Moreira county, state of Minas Gerais, in the summer 2006. Disturbed and undisturbed soil samples were collected to determine chemical ( $p H, P, K$, Ca, $M g, A l, H+A l, S B, t, T, V, m$, organic matter), physical (soil bulk density, soil particle density, flocculation index, mean weight diameter, macro and microporosity) and microbial attributes (microbial activity, $q \mathrm{CO}_{2}$, microbial biomass, relation microbial biomass/organic carbon). Based on visual aspects related to soil, plants and animals, a visual quality index was calculated for each ecosystem, which proved practical, simple and sensitive to the different vegetation covers. The great majority of the physical and microbial attributes was efficient to evaluate the environmental quality, and indicated high dissimilarity between the pasture and the other ecosystems, and great similarity between the Eucalyptus ecosystem with a well developed understory and that of planted Araucaria.
\end{abstract}

Index terms: Araucaria, Eucalyptus, soil quality indicators.

\section{INTRODUÇÃO}

Tem sido freqüente, no Brasil, o esgotamento das reservas florestais de araucária em função de sua exploração predatória pelas indústrias madeireiras e pela prática de agricultura de baixa tecnologia com utilização de queimadas. A araucária é uma das espécies nativas de grande valor silvicultural e econômico para o País e está na lista oficial de espécies da flora brasileira ameaçadas de extinção, sendo classificada pelo IBAMA como vulnerável (Maior, 1997).

Apesar de o assunto ser extremamente polêmico, de acordo com Silva Júnior et al. (1995), tem havido prioridade em restaurar áreas de vegetação nativa com plantações de eucalipto, com o objetivo de proteger fontes de água, resguardar a fauna local e oferecer alternativas para controle de doenças e pragas, criando um local para seus predadores. A grande maioria das áreas ocupadas por essas espécies está sobre solos muito intemperizados e lixiviados, portanto com baixa disponibilidade natural de nutrientes. $\mathrm{O}$ atendimento da demanda nutricional das árvores é bastante prejudicado pela alta deficiência hídrica que ocorre na maior parte das áreas.

A expansão do cultivo de eucalipto nas áreas de relevo mais acidentado do sul de Minas Gerais, bem como na região de solos de baixa fertilidade da região do Campos das Vertentes de Minas, tem levado a uma evidente mudança dessas paisagens com conseqüentes alterações na qualidade dos solo.

Alguns estudos têm sido desenvolvidos para avaliar os atributos dos solos em diferentes condições de uso (van den Berg, 1995; Alvarenga, 1996). Estudando um Latossolo Vermelho-Escuro distrófico textura muito argilosa, a segunda autora observou que, no tocante a indicadores de impactos no solo, alguns atributos foram bastante sensíveis às alterações provocadas pelos sistemas de manejo adotados, entre os quais a densidade do solo, a relação entre porosidade total e microporosidade, a estabilidade de agregados em água, os teores de $\mathrm{C}$ do solo, a soma e a saturação por bases no solo, saturação por $\mathrm{Al}$, teores de micronutrientes (B, Mn e $\mathrm{Zn}$ ), o C microbiano e a relação $\mathrm{C}$ microbiano/C orgânico do solo, e a diversidade biológica medida pela presença de fungos micorrízicos. Apesar de esses atributos indicarem impactos nos sistemas avaliados (Cerrado nativo versus floresta de eucalipto jovem e adulto, pasto nativo, pasto implantado e cultivo anual intensivo), a autora observou que ainda é premente a necessidade de estabelecer níveis que indiquem os limites em que as alterações sejam degradativas ou interfiram no equilíbrio dinâmico do ambiente.

Sendo o solo um recurso natural, o uso de indicadores da sua qualidade para avaliação da sustentabilidade ambiental é de grande importância. A qualidade do solo pode ser definida como sua capacidade de funcionar dentro dos limites do ecossistema para sustentar a produtividade biológica, manter a qualidade ambiental e promover a saúde vegetal e animal (Doran et al., 1996). A avaliação dessa qualidade por meio de atributos do solo é bastante complexa devido à grande quantidade de definições de um solo com qualidade para determinado uso, à multiplicidade de inter-relações entre fatores físicos, químicos e biológicos que controlam os processos e aos aspectos relacionados à sua variação no tempo e no espaço. 
O grande desafio dos estudos sobre sustentabilidade é com relação ao desenvolvimento de métodos para avaliação da qualidade do solo e do ambiente sob a interferência do homem. Há, atualmente, um esforço multidisciplinar, tentando quantificar diferentes atributos que estão relacionados com a sustentabilidade, traduzindo-os na forma de indicadores de qualidade do solo. Segundo Tótola \& Chaer (2002), um indicador de qualidade do solo pode ser simplesmente uma variável mensurável (temperatura do solo), um processo (taxa de mineralização do N) ou um índice, no qual se incluem inúmeras medidas do solo (densidade, porosidade, matéria orgânica e outros).

Observa-se que, quando as variáveis ambientais (atributos físicos, químicos e biológicos) do solo são analisadas em conjunto e correlacionadas com diferentes ecossistemas, a visualização e a ordem de influência dessas variáveis são bem mais claras. A idéia de utilizar técnicas estatísticas que permitam a ordenação de amostras em função de uma série de fatores ambientais simultaneamente permite uma análise conjunta dos fatores ambientais para verificação de suas correlações com diferentes ecossistemas ou usos do solo. Alvarenga (1996), estudando a alteração de atributos de solo sob diferentes condições de uso, observou, por meio de análise de componentes principais, que os atributos do solo mais correlacionados com as alterações nos ecossistemas foram o teor de $\mathrm{K}, \mathrm{Mg}$, Ca e S, a densidade do solo, a porosidade total, a macroporosidade e a percentagem de agregados superiores a $2 \mathrm{~mm}$. A autora observou ainda que, na floresta de eucalipto com 15 anos de plantio, houve aumento nos teores de $\mathrm{Ca}, \mathrm{Mg}$ e B. Nas propriedades biológicas, encontraramse uma diversidade maior, colonização radicular mais extensa e maior número de esporos dos fungos micorrízicos arbusculares. Observou, ainda, que o eucalipto com cortes espaçados (15 anos) e a pastagem de braquiária, apesar de alterarem os atributos químicos do solo, apresentaram menor degradação física, com menor alteração da qualidade ambiental que os demais sistemas estudados.

Avaliando a agregação do solo e a estabilidade dos agregados em diferentes sistemas de manejo do solo, incluindo lavouras em plantio direto, lavouras (soja) em rotação com pastagens em plantio direto e pastagens permanentes de Brachiaria sp., Salton et al. (2008) obtiveram agregados maiores e mais estáveis em solos com pastagens, com forte efeito dos teores de argila e de $\mathrm{C}$ no solo. A formação de macroagregados pareceu estar relacionada à presença de raízes mais abundantes sob pastagem de gramíneas.

Segundo Silva et al. (2008), estudos de qualidade física e estrutural do solo, com influência direta no crescimento e desenvolvimento das raízes das plantas, podem ser facilitados por meio da representação matemática de curvas de retenção de água e de resistência do solo à penetração. Solos sob cultivo de cana-de-açúcar com diferentes texturas foram selecionados para esse estudo e, após ajustes das curvas de retenção de água e de resistência do solo à penetração em função dos teores de argila, verificouse que o acréscimo do teor de argila no solo reduziu a amplitude da densidade deste para manter o mesmo valor de resistência do solo à penetração em potenciais mátricos equivalentes.

Estudos da avaliação de atributos químicos, físicos e biológicos na qualidade do solo são essenciais no entendimento da funcionalidade e sustentabilidade de solos em diferentes condições de uso. Utilizando ferramentas de agrupamento e análise multivariada, objetivou-se, neste estudo, identificar e quantificar efeito(s) de importantes coberturas florestais e de pastagem na qualidade química, física, microbiana e visual de solos no sul de Minas Gerais.

\section{MATERIAL E MÉTODOS}

\section{Definição e caracterização das áreas}

O trabalho foi realizado em áreas adjacentes a uma propriedade particular rural, no município de Delfim Moreira, MG, definidas em função da proximidade de diferentes ecossistemas. As seguintes áreas foram selecionadas: (a) área com floresta de eucalipto ( $E$. grandis) implantada em espaçamento de 3 × $3 \mathrm{~m}$, em estádio avançado de desenvolvimento, com sub-bosque bem desenvolvido, com espécies da Mata Atlântica; (b) área com floresta de araucária (A. angustifolia) implantada em espaçamento de $2 \times 2 \mathrm{~m}$, com cerca de 35 anos de idade, sem sub-bosque; (c) área de pastagem com braquiária (B. decumbens), em condição de submanejo, com espécies sucessionais; e (d) área de vegetação natural, com espécies da Mata Atlântica, sem interferência antrópica, margeando a área de pastagem.

Pelo fato de a área com espécies da Mata Atlântica apresentar em torno de 1,2 ha, áreas similares foram selecionadas no outros ecossistemas, com amostragem no verão de 2006. Cada ecossistema foi subdividido em três subáreas, cada uma com $1 / 3$ da área total de cada ecossistema. Coletaram-se quatro amostras deformadas, em ziguezague, por subárea, perfazendo uma amostra composta. No total, foram coletadas três amostras compostas por área, na profundidade de $0-20 \mathrm{~cm}$, e cada amostra composta considerada uma repetição por ecossistema estudado. Nestas amostras, determinaram-se: (a) densidade de partículas; (b) textura; (c) estabilidade de agregados; (d) C da biomassa microbiana; e (e) atividade da biomassa microbiana do solo (respiração basal) após peneiramento em malha de $2 \mathrm{~mm}$.

Uma amostra composta por área foi submetida à caracterização química. Para isso, as amostras de solo foram secas em estufa $\left(65^{\circ} \mathrm{C}\right)$ até peso constante 
e peneiradas em malha de $2 \mathrm{~mm}$ para avaliação do pH em água na relação 1:2,5 (solo:água); $\mathrm{Ca}, \mathrm{Mg}, \mathrm{e} \mathrm{Al}$ trocáveis extraídos com $\mathrm{KCl} 1 \mathrm{~mol} \mathrm{~L}^{-1}$, analisados por titulometria; P e K extraídos pelo método Mehlich $1 \mathrm{e}$ analisados por colorimetria e fotometria de chama, respectivamente. A matéria orgânica foi determinada por colorimetria, utilizando o método Walkley e Black (Quadro 1). Todos os métodos utilizados encontramse descritos em Embrapa (1997).

Nas mesmas subáreas, coletaram-se amostras indeformadas com amostrador de Uhland (Blake \& Hartge, 1986), utilizando-se anéis de 0,0652 $\mathrm{m}$ de diâmetro por $0,0254 \mathrm{~m}$ de altura, num total de três amostras por área, nas quais se determinaram: (a) densidade de solo e (b) macro e microporosidade.

\section{Avaliação dos atributos físicos do solo}

Com as amostras deformadas, determinaram-se a densidade de partículas pelo método do balão volumétrico; a textura e a classe textural pelo método da pipeta e Diagrama Triangular simplificado; e a estabilidade de agregados por peneiramento seco, calculando-se, posteriormente, o diâmetro médio geométrico. Nas amostras indeformadas, determinaram-se a densidade do solo pelo método do anel volumétrico, e a micro e macroporosidade pelo método da mesa de tensão. Esses métodos estão descritos em Embrapa (1997).

\section{Avaliação dos atributos microbianos do solo}

O C da biomassa foi determinado segundo Ferreira et al. (1999), empregando-se o método da irradiação/ incubação, que apresenta como princípio básico a eliminação de microrganismos por meio da irradiação eletromagnética de forno de microondas, antes da avaliação da quantidade de $\mathrm{CO}_{2}$ liberada após incubação por 10 dias, $25^{\circ} \mathrm{C}$. A atividade respiratória da biomassa microbiana, ou respiração basal do solo, foi avaliada pela quantificação do $\mathrm{CO}_{2}$ liberado durante a incubação do solo em sistema fechado, onde o $\mathrm{CO}_{2}$ foi capturado em solução de $\mathrm{NaOH} 1 \mathrm{~mol} \mathrm{~L}^{-1}$ e posteriormente titulada com $\mathrm{HCl} 1 \mathrm{~mol} \mathrm{~L}^{-1}$, segundo método adaptado de Anderson (1982).

$\mathrm{O}$ quociente metabólico $\left(q \mathrm{CO}_{2}\right)$ foi obtido pela relação entre atividade microbiana (respiração basal) e $\mathrm{C}$ da biomassa microbiana, expressa em quantidade de $\mathrm{CO}_{2}$ por $\mathrm{C}$ da biomassa por tempo (Anderson \& Domsch, 1993).

O quociente $\mathrm{C}$ microbiano/C orgânico foi calculado pela relação entre o $\mathrm{C}$ da biomassa microbiana e $\mathrm{C}$ orgânico do solo (Brookes, 1995), o último fornecido após análise química das amostras de solo.

\section{Índice de qualidade visual (IQV) dos ecossistemas}

O IQV foi calculado utilizando-se uma planilha desenvolvida no Laboratório de Microbiologia do Solo da Universidade Federal de Lavras (Carneiro, 2000; Melloni, 2001), após atribuição de notas aos diferentes ecossistemas, por três avaliadores. As notas variaram de 0 a 5 , e os indicadores visuais utilizados foram: presença de erosão, pedregosidade, macrofauna do solo, índice de cobertura vegetal, diversidade, porte/ estratificação, vigor da vegetação, presença e estado de decomposição da serapilheira, incorporação da serapilheira no solo e fauna silvestre. Em função da importância de cada indicador para a qualidade do solo, eles foram corrigidos (ponderados) antes da soma dos valores. A ponderação foi feita da seguinte forma: erosão $100 \%$ da nota atribuída, pedregosidade $50 \%$, fauna $50 \%$, índice de cobertura $100 \%$, índice de diversidade $80 \%$, porte/estratificação $50 \%$, vigor da vegetação $100 \%$, quantidade de serapilheira $100 \%$, estado de decomposição da serapilheira $100 \%$, incorporação da serapilheira $70 \%$, sucessão na vegetação $100 \%$, presença de fauna silvestre $50 \%$.

Quadro 1. Caracterização química das amostras de solo dos diferentes ecossistemas

\begin{tabular}{|c|c|c|c|c|c|}
\hline Indicador & Unidade & Eucalipto & Pastagem & Mata & Araucária \\
\hline & & & \multicolumn{2}{|c|}{ Atributos químicos } & \\
\hline $\mathrm{pH}$ & - & 4,5 & 5,6 & 4,6 & 4,8 \\
\hline $\mathrm{P}$ & $m g \mathrm{dm}^{-3}$ & 5,8 & 43,4 & 4,0 & 2,3 \\
\hline $\mathrm{K}$ & $\mathrm{mg} \mathrm{dm}{ }^{-3}$ & 76,0 & 168,0 & 83,0 & 73,0 \\
\hline $\mathrm{Ca}^{2+}$ & $\mathrm{cmol}_{\mathrm{c}} \mathrm{dm}^{-3}$ & 0,6 & 2,4 & 1,0 & 0,8 \\
\hline $\mathrm{Mg}^{2+}$ & $\mathrm{cmol}_{\mathrm{c}} \mathrm{dm}^{-3}$ & 0,3 & 1,1 & 0,5 & 0,5 \\
\hline $\mathrm{Al}^{3+}$ & $\mathrm{cmol}_{\mathrm{c}} \mathrm{dm}^{-3}$ & 3,1 & 0,2 & 1,4 & 1,6 \\
\hline $\mathrm{H}+\mathrm{Al}$ & $\mathrm{cmol}_{\mathrm{c}} \mathrm{dm}^{-3}$ & 21,4 & 6,3 & 13,7 & 12,3 \\
\hline SB & $\mathrm{cmol}_{\mathrm{c}} \mathrm{dm}^{-3}$ & 1,1 & 3,9 & 1,7 & 1,5 \\
\hline $\mathrm{t}$ & $\mathrm{cmol}_{\mathrm{c}} \mathrm{dm}^{-3}$ & 4,2 & 4,1 & 3,1 & 3,1 \\
\hline $\mathrm{T}$ & $\mathrm{cmol}_{\mathrm{c}} \mathrm{dm}^{-3}$ & 22,5 & 10,2 & 15,4 & 13,8 \\
\hline $\mathrm{V}$ & $\%$ & 4,8 & 38,4 & 11,1 & 10,8 \\
\hline $\mathrm{m}$ & $\%$ & 74 & 5 & 45 & 52 \\
\hline MO & dag kg-1 & 8 & 4,9 & 5,8 & 6,7 \\
\hline
\end{tabular}




\section{Análise dos resultados}

A análise de variância e a comparação das médias foram feitas por Duncan a $5 \%$, utilizando-se o programa estatístico SANEST (Zonta et al., 1984). Posteriormente, as áreas foram agrupadas em dendrogramas de similaridade, conforme os seus atributos físicos, químicos e microbianos, utilizandose o método Complete Linkage e Distância Euclidiana (Everitt, 1993), pelo programa STATISTICA 5.0 (1995).

Os valores médios dos atributos físicos e microbianos, em conjunto com os atributos químicos obtidos das amostras de solo, foram utilizados para análise de componentes principais (PCA) por meio do programa PC-ORD 3.12 (McCune \& Mefford, 1997).

\section{RESULTADOS E DISCUSSÃO}

Quanto aos atributos físicos, os valores da densidade do solo foram maiores nos ecossistemas (ec.) araucária e pastagem e menores nos eucalipto e mata. A densidade de partículas foi menor no mata e maior e igual em todos os demais ecossistemas. O índice de floculação foi maior nos ec. mata e araucária, e posteriormente nos ec. pastagem e eucalipto. O diâmetro médio geométrico dos agregados foi maior nos ec. araucária e mata e posteriormente nos ec. eucalipto e pastagem. A microporosidade não diferiu entre os ecossistemas, enquanto a macroporosidade foi maior no ec. mata, seguido pelos demais ecossistemas (Quadro 2). Por esses resultados, a pastagem apresentou fragilidade física, com problema de compactação e exposição do solo a processos erosivos. Em contrapartida, o ec. mata foi o ecossistema que, no geral, apresentou as melhores condições físicas, demonstrando tratar-se de um ambiente mais conservado e protegido de ações antrópicas. Portanto, eucalipto e araucária podem ser considerados ecossistemas com qualidade física intermediária, apesar de o segundo apresentar agregados maiores e mais estáveis em água.

Quanto aos atributos microbianos, a atividade microbiana e $q \mathrm{CO}_{2}$ foram maiores no eucalipto e, posteriormente, no ec. araucária, em relação aos demais ecossistemas (Quadro 2). Esses ecossistemas apresentaram ainda os menores valores do quociente C microbiano/C orgânico. Esses resultados demonstram que, embora o eucalipto apresente maior atividade microbiana, o ambiente é mais estressante para os microrganismos do solo, visto o maior valor de $q \mathrm{CO}_{2}$. A utilização de $q \mathrm{CO}_{2}$ pode ser uma ferramenta significativa para a quantificação da influência de fatores externos nos microrganismos do solo, principalmente relacionados ao desempenho funcional de comunidades microbianas em certas condições e ao impacto de diferentes estratégias de manejo de solos (Anderson \& Domsch, 1993). O qCO pode, ainda, indicar a estrutura da comunidade, sua relação com a atividade de microrganismos e se o surgimento ou desaparecimento de populações microbianas, em termos de energia, é vantajoso ou não ao funcionamento do ecossistema em estudo. Esse indicador tem se mostrado altamente sensível na discriminação de diferentes ambientes (Silveira et al., 2006), facilitando as conclusões referentes ao emprego de análises químicas e físicas conjuntas na avaliação da qualidade de ambientes.

Contrariamente, o ecossistema mata apresentou o menor valor $q \mathrm{CO}_{2}$ e a maior relação $\mathrm{C}$ microbiano/C orgânico, indicando se tratar de ecossistema com maior densidade microbiana sob equilíbrio e baixo estresse ambiental advindo, provavelmente, das melhores condições físicas do solo. $\mathrm{O}$ ec. pastagem ficou

Quadro 2. Atributos físicos e microbianos do solo nos diferentes ecossistemas estudados

\begin{tabular}{|c|c|c|c|c|c|}
\hline Indicador & Unidade & Eucalipto & Pastagem & Mata & Araucária \\
\hline \multicolumn{6}{|c|}{ Atributos físicos } \\
\hline Densidade do solo & $\mathrm{kg} \mathrm{dm}^{-3}$ & $1,06 b^{(1)}$ & $1,36 \mathrm{a}$ & $0,94 \mathrm{~b}$ & $1,28 \mathrm{a}$ \\
\hline Diâmetro de partículas & $\mathrm{kg} \mathrm{dm}^{-3}$ & $2,35 \mathrm{a}$ & $2,34 \mathrm{a}$ & $2,15 \mathrm{~b}$ & $2,45 \mathrm{a}$ \\
\hline Índice de floculação & $\%$ & $50,00 \mathrm{c}$ & $73,00 \mathrm{~b}$ & $93,33 \mathrm{a}$ & $91,12 \mathrm{a}$ \\
\hline $\begin{array}{l}\text { Diâmetro médio } \\
\text { geométrico }\end{array}$ & $\mathrm{mm}$ & $0,73 b$ & $0,37 \mathrm{c}$ & $0,62 b$ & $1,13 \mathrm{a}$ \\
\hline Microporosidade & $\%$ & $33,29 \mathrm{a}$ & $32,68 \mathrm{a}$ & $24,95 \mathrm{a}$ & $34,72 \mathrm{a}$ \\
\hline Macroporosidade & $\%$ & $20,81 b$ & $13,53 \mathrm{~b}$ & $34,31 \mathrm{a}$ & $16,52 \mathrm{~b}$ \\
\hline \multirow[t]{2}{*}{ Classe textural } & - & média a argilosa & média a argilosa & argilosa & argilosa a muito argilosa \\
\hline & \multicolumn{5}{|c|}{ Atributos microbianos } \\
\hline Atividade microbiana & $\mathrm{mg}(40 \mathrm{~g})^{-1}$ de $\mathrm{C}-\mathrm{CO}_{2}$ no solo & $81,67 \mathrm{a}$ & $44,8 \mathrm{bc}$ & $34,53 \mathrm{c}$ & $62,3 \mathrm{ab}$ \\
\hline $\mathrm{qCO}_{2}$ & (mg $\mu \mathrm{g}^{-1}$ de $\mathrm{C}-\mathrm{CO}_{2}$ do C-biomassa) $\times 10$ & $1,59 \mathrm{a}$ & $0,86 \mathrm{bc}$ & $0,51 \mathrm{c}$ & $1,1 \mathrm{~b}$ \\
\hline $\begin{array}{l}\text { Carbono da biomassa } \\
\text { microbiana (CBM) }\end{array}$ & $\mu \mathrm{g} \mathrm{g}^{-1}$ de C no solo & $64,30 \mathrm{a}$ & $64,30 \mathrm{a}$ & $116,15 \mathrm{a}$ & $58,07 \mathrm{a}$ \\
\hline Relação CBM/C orgânico & $\%$ & 0,14 & 0,23 & 0,35 & 0,15 \\
\hline
\end{tabular}

(1) Médias na linha seguidas pela mesma letra não diferem estatisticamente entre si, a $5 \%$, por Duncan. 
numa posição intermediária quanto aos aspectos microbianos, mais próximo do ec. mata do que dos demais ecossistemas. Esse efeito pode estar ligado às melhores condições químicas dos solos desse ecossistema (Quadro 1).

$O$ resultado discrepante da fertilidade do solo no ecossistema pastagem deve-se ao fato de ser o único atualmente sob interferência antropogênica (adição de corretivos e fertilizantes) e utilização na criação de animais. No entanto, mesmo em situação diferenciada em relação aos demais ecossistemas com melhores condições químicas, seus atributos físicos não acompanharam a fertilidade. Esse resultado indica que a qualidade dos solos não pode ser considerada somente pelos seus aspectos químicos. Alvarenga (1996), corroborando os resultados encontrados neste estudo, também observou que ecossistemas que não receberam constante aporte de nutrientes apresentaram propriedades químicas desfavoráveis em relação ao ecossistema original, sendo esses efeitos mais evidentes para o $\mathrm{C}, \mathrm{Ca}, \mathrm{K}, \mathrm{Mn}, \mathrm{B}$, saturação por bases, Al trocável e saturação por Al. Além disso, considerando que maior intensidade de atividade biológica ocorre na camada superficial do solo, a sua exposição aos processos erosivos, com remoção de material do solo devido ao uso e, ou, manejo inadequados, provoca o seu empobrecimento. Esperase, portanto, que em ambientes onde os processos de degradação do solo, como erosão, são menos intensos, a atividade dos organismos seja maior. Segundo a autora, solos sob diferentes usos diferiram quanto aos atributos físicos, químicos e biológicos, em relação à vegetação nativa (Cerrado), sendo as diferenças mais evidentes na camada superficial do solo.

As médias dos valores obtidos na avaliação in situ de aspectos ligados ao solo, às plantas e aos animais estão demonstradas no quadro 3, e os valores totais expressos como índices de qualidade visual, na figura 1.
Em virtude das melhores condições visuais de qualidade de solo, plantas e animais da mata, considerou-se esse ecossistema como referência. Calculando-se os déficits em relação à referência, os ecossistemas pastagem, araucária e eucalipto apresentaram valores de 54,5, 38,2, e 15,7\%, respectivamente. Apesar de a pastagem apresentar excelente percentagem de cobertura vegetal, mostrou grande déficit ligado à fauna do solo e, principalmente, à vegetação, com as piores condições visuais de diversidade, porte, vigor, sucessão (considerados normais para pastagem) e aspectos considerados da serapilheira. O ecossistema araucária apresentou baixa cobertura e diversidade vegetal, com baixos valores relacionados à serapilheira. Já o eucalipto, em relação ao ec. mata, apesar de excelentes qualidades visuais, apresentou menor diversidade e estratificação vegetal e baixa incorporação da serapilheira ao solo. Embora seja evidente o grau de subjetividade intrínseco ao método de análise visual, pela sua elevada capacidade discriminatória, praticidade e baixo custo, esta pode ser utilizada em estudos da qualidade

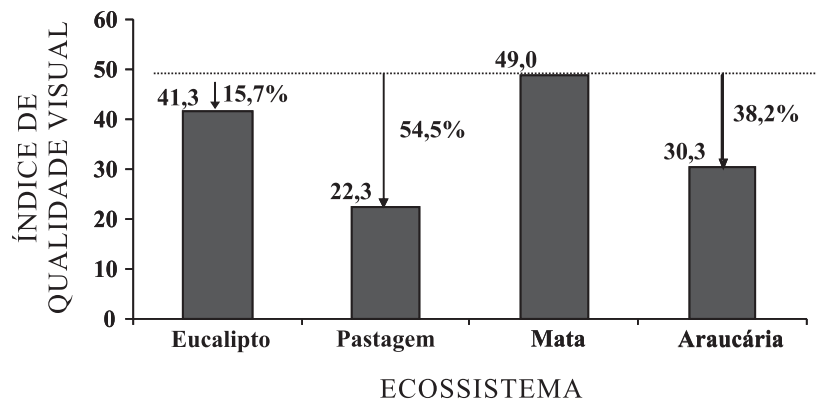

Figura 1. Índices de qualidade visual nos diferentes ecossistemas de estudo, obtidos por meio de atributos da qualidade do solo, fauna vegetação. As setas indicam os respectivos déficits dos valores (em percentagem) dos ecossistemas com relação à referência (mata).

Quadro 3. Valores ponderados das notas atribuídas aos aspectos de solo, plantas e animais durante a avaliação visual dos diferentes ecossistemas

\begin{tabular}{|c|c|c|c|c|}
\hline \multirow{2}{*}{ Aspecto } & \multicolumn{4}{|c|}{ Médias dos valores ponderados } \\
\hline & Eucalipto & Araucária & Pastagem & Mata \\
\hline Erosão & 5 & 5 & 5 & 5 \\
\hline Pedregosidade & 2,5 & 2,5 & 2,5 & 5 \\
\hline Fauna do solo & 2 & 1 & 0,5 & 2 \\
\hline Percentagem de cobertura vegetal & 3 & 2 & 5 & 3 \\
\hline Diversidade vegetal & 4 & 2,4 & 1,6 & 5 \\
\hline Porte ou estratificação da vegetação & 2,5 & 1,5 & 0,5 & 5 \\
\hline Vigor da vegetação & 5 & 5 & 3 & 5 \\
\hline Sucessão da vegetação & 5 & 3 & 1 & 4 \\
\hline Quantidade de serapilheira & 5 & 3 & 1 & 5 \\
\hline Estado & 4 & 3 & 1 & 5 \\
\hline Incorporação da serapilheira ao solo & 2,8 & 1,4 & 0,7 & 4 \\
\hline Fauna silvestre no ambiente & 0,5 & 0,5 & 0,5 & 1 \\
\hline Notas finais & 41,3 & 30,3 & 22,3 & 49,0 \\
\hline
\end{tabular}


ambiental, fornecendo informações relacionadas ao diagnóstico e possibilitando a indicação de manejos específicos, visando alcançar sustentabilidade e qualidade ambiental. Ressalta-se também a importância da utilização desse método nos estudos de impacto ambiental, para favorecer diagnósticos rápidos para a indicação de alternativas de uso com menor degradação do ambiente.

Com as médias dos atributos físicos e microbianos, aliadas aos valores dos atributos químicos e visuais, os ecossistemas foram submetidos à análise de agrupamento (Figura 2).

Os ecossistemas eucalipto e araucária apresentaram maior similaridade, em torno de $60 \%$ e $35 \%$ em relação ao mata. Não se observou similaridade de qualquer um desses ecossistemas com o ec. pastagem (0 \% de similaridade ou $100 \%$ dissimilaridade). Essas diferenças de agrupamento são resultado, portanto, das diferenças dos atributos observadas (Quadros 1,2 e 3), possibilitando uma análise mais generalizada da qualidade dos ecossistemas. Os atributos que promoveram a ausência de similaridade da pastagem com os demais ecossistemas e, contrariamente, a grande proximidade dos ecossistemas eucalipto e araucária, e destes com o ec. mata, podem ser evidenciados nos resultados da análise multivariada (Figura 3).

Os componentes principais (PC1 e PC2) compuseram $87,82 \%$ da variância total dos dados, $\mathrm{PC} 1$ apresentou 55,31 \% da variância total e o PC2 compôs $32,51 \%$. Em vista desses altos valores, somente os dois PCs serão mostrados e discutidos. Pode-se notar, inicialmente, a grande separação espacial da pastagem em relação aos demais ecossistemas. Essa separação é facilmente evidenciada pelos aspectos visuais estudados, cujo IQV (índice de qualidade visual) foi bem discriminatório (Figura 1). Além desse, os atributos químicos ligados à fertilidade $\left(\mathrm{P}, \mathrm{K}, \mathrm{Ca}^{2+}, \mathrm{Mg}^{2+}, \mathrm{pH}\right.$, $\mathrm{SB}$ e V), além da densidade do solo (DS), promoveram a separação do pastagem dos demais ecossistemas. Esse resultado indica que nem sempre há estreita relação entre qualidade física e química do solo com a qualidade visual dos ecossistemas e os atributos microbianos.

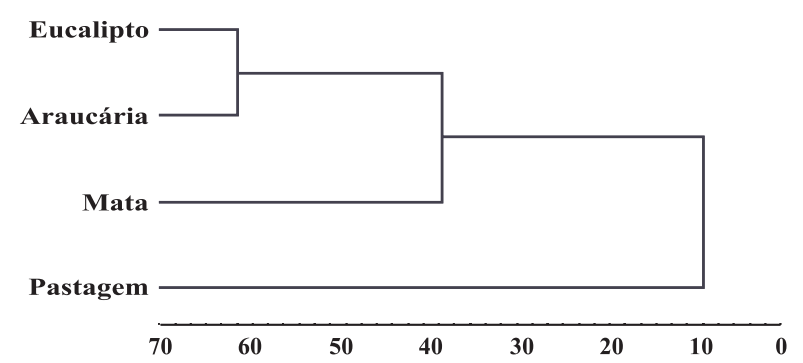

Figura 2. Dendrograma de similaridade construído com as médias dos atributos físicos e microbianos e os valores dos atributos químicos do solo e visuais dos diferentes ecossistemas estudados
No entanto, o atributo matéria orgânica (MO) esteve fortemente relacionado aos demais ecossistemas, posicionando-se em sentido contrário ao da pastagem. AMO tem sido considerada fator-chave e um dos mais sensíveis e críticos indicadores da qualidade do solo em função de suas inúmeras participações no funcionamento de ecossistemas (Sikora \& Stott, 1996). A avaliação da qualidade ambiental deve sempre ser definida em função da maior quantidade possível de indicadores, recomendando-se, entre eles, a MO.

Pela análise multivariada, evidenciou-se a diferenciação entre o ecossistema mata do eucalipto e araucária, reflexo dos maiores valores de $\mathrm{C}$ da biomassa, quociente $\mathrm{C}$ da biomassa e $\mathrm{C}$ orgânico e macroporosidade (Figura 3). Assim como a própria biomassa, o quociente $\mathrm{C}$ da biomassa e $\mathrm{C}$ orgânico do solo tem sido utilizada como indicador de alterações do solo, sendo menor em condições estressantes (Marchiori Júnior \& Melo, 1999; Souza \& Melo, 2003), como no eucalipto e araucária. Segundo Sparling (1992), mudanças nessas relações refletem o padrão

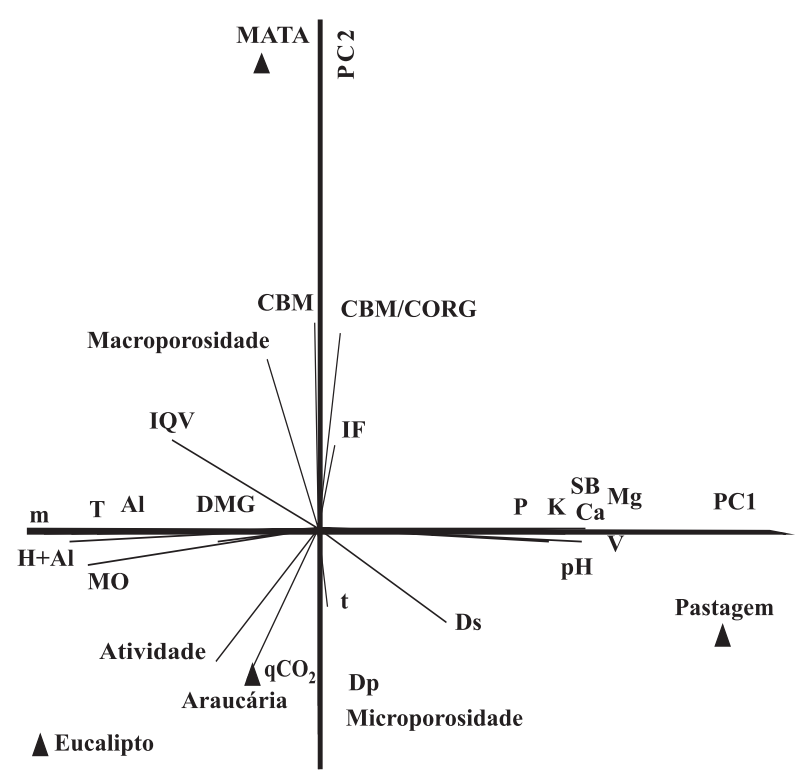

Figura 3. Análise de componentes principais das médias dos atributos físicos e microbianos em conjunto com os valores dos atributos químicos do solo e visuais dos diferentes ecossistemas estudados (A). Físicos: IF (índice de floculação), Ds (densidade do solo), Dp (densidade de partículas), DMG (diâmetro médio geométrico). Microbianos: Atividade (atividade microbiana ou respiração basal), qCO (quociente metabólico), CBM (C da biomassa microbiana), CBM/CORG (quociente entre $\mathrm{C}$ da biomassa microbiana e $\mathrm{C}$ orgânico do solo). Químicos: MO (matéria orgânica), SB (soma de bases), V (saturação por bases), $\mathrm{m}$ (saturação por alumínio), $\mathrm{H}+\mathrm{Al}$, T (CTC a pH 7,0), t (CTC efetiva). IQV: índice de qualidade visual. 
de entrada de matéria orgânica nos solos estudados, a eficiência de conversão do $\mathrm{C}$ microbiano, perdas do $\mathrm{C}$ do solo e estabilização do C orgânico pela fração mineral do solo (Souza \& Melo, 2003).

De acordo com Alvarenga et al. (1999), além das características do solo e da serapilheira, a exposição do solo à erosão diminui a biomassa microbiana. Fernandes \& Cardoso (1995), comparando solos sob plantio convencional e plantio direto, observaram que no último os valores de matéria orgânica, $\mathrm{P}, \mathrm{Ca}, \mathrm{Mg}$ e biomassa foram maiores. Isso pode explicar os menores valores de biomassa e $\mathrm{C}$ na pastagem, resultados que estão de acordo com aqueles encontrados por Habte (1989) e Alvarenga (1996). Com isso, salientam-se as maiores contribuições da biomassa microbiana na sustentabilidade do ec. mata, cujo ecossistema, apesar das proximidades físicas, químicas e visuais com os demais ecossistemas, se mantém fortemente funcional em função da microbiota do solo.

Apesar das condições estressantes dos microorganismos do solo $\left(q \mathrm{CO}_{2}\right)$ apresentados pelo eucalipto, verificou-se que, no contexto geral, a qualidade ambiental desse ecossistema pouco diferiu daquela apresentada pela araucária (Figura 3). Cabe enfatizar que o ecossistema eucalipto caracterizava-se pela espécie $E$. grandis, pela idade avançada e plantio não adensado, possibilitando o surgimento de um subbosque diversificado. Esse resultado concorda com o obtido anteriormente por Melloni et al. (2003, 2006) e Carneiro (2000), os quais obtiveram alta diversidade funcional e atividade bioquímica de microrganismos em áreas de mineração de bauxita em reabilitação, utilizando eucalipto menos adensado e com sub-bosque desenvolvido.

Silva Júnior et al. (1995) observaram que, após dez anos, a presença de $E$. grandis não reduziu a diversidade de espécies na regeneração do sub-bosque, além de favorecer o estabelecimento de uma comunidade jovem, característica de um avanço do estádio de sucessão. Concluíram que o plantio de $E$. grandis pode providenciar um grau de sombra necessário para a regeneração de florestas de espécies naturais, parecendo que a não-alelopatia do $E$. grandis age como um "berçário" de espécies arbóreas, tendo o papel que pode, provavelmente, ser tomado pela Cecropia spp e outras espécies pioneiras sob condição natural. Assim, plantações de E. grandis podem ser um meio efetivo de promover a regeneração natural e recuperar formações vegetais naturais.

Avaliando a composição da serapilheira de diferentes coberturas vegetais em iguais condições de solo e clima, Alvarenga (1996) observou que as espécies vegetais diferem na eficiência em aproveitar os nutrientes do solo, na medida em que variam as suas necessidades específicas e sua capacidade de adaptação à condição de disponibilidade de nutrientes. Observou que a serapilheira do Cerrado apresentou os maiores teores de nutrientes ( $\mathrm{P}, \mathrm{K}, \mathrm{Ca}$ e $\mathrm{Mg}$ ), também encontrados mais disponíveis no solo, exceto para o B, que se apresentou em maior teor na serapilheira de eucalipto adulto em relação às demais coberturas vegetais comparadas. Essa diferença foi associada à grande diversidade de espécies no Cerrado e no subbosque do eucalipto adulto, que promovem diferenças na qualidade da serapilheira.

Considerando que a formação de florestas mistas via consórcio restabelece as funções ecológicas básicas das florestas plantadas (biodiversidade, reprodução das espécies, dinâmica sucessional do ecossistema), o plantio de espécies do gênero Eucalyptus, após dez anos, produz sub-bosque bastante diversificado e pode ser considerado restabelecido ou, pelo menos, em processo de restabelecimento. Conclui-se que, com o tempo, o ecossistema, apesar de alterado, assim atinge um estádio de equilíbrio semelhante às condições naturais.

Em relação à função de proteção, o plantio de Eucalyptus sp. deve resultar na melhoria dos atributos físicos do solo, como decorrência da ação benéfica da incorporação de matéria orgânica, melhorando principalmente a estrutura, capacidade de armazenamento de água, infiltração e aeração. Nesse sentido, Singh \& Banerjee (1980) estudaram diferentes condições de microagregação de solos sob diversas espécies florestais e em solos agrícolas. Obtiveram melhor agregação nas amostras de solos florestais e, no que se relaciona ao diâmetro dos agregados maiores que 2,00 mm, o solo sob eucalipto mostrou-se melhor do que sob Pinus.

Com isso, nas condições deste estudo, pode-se enfatizar que solos sob eucalipto (planta exótica) apresentaram grande proximidade daqueles sob araucária (planta nativa), reforçando o papel do primeiro ecossistema, quando conduzido em maiores espaçamentos e com sub-bosque, na qualidade ambiental de ecossistemas no sul de Minas Gerais.

\section{CONCLUSÕES}

1. Com exceção da microporosidade e do $\mathrm{C}$ da biomassa microbiana, a grande maioria dos indicadores físicos e microbianos mostrou-se eficiente na discriminação dos diferentes ecossistemas, sendo, portanto, recomendados em estudos da qualidade ambiental de ecossistemas similares.

2. O índice de qualidade visual, que se destaca pela praticidade e simplicidade de avaliação, juntamente com o teor de matéria orgânica, foram eficientes e discriminatórios dos ecossistemas com coberturas florestais e aquele com pastagem.

3. O ecossistema eucalipto, conduzido em espaçamento que permite o desenvolvimento de subbosque, mostrou-se muito semelhante ao ecossistema araucária implantada. 


\section{LITERATURA CITADA}

ALVAREnGA, M.I.N. Propriedades físicas, químicas e biológicas de um Latossolo Vermelho-Escuro em diferentes ecossistemas. Lavras, Universidade Federal de Lavras, 1996. 211p. (Tese de Doutorado)

ALVARENGA, M.I.N.; SIQUEIRA, J.O. \& DAVIDE, A.C. Teor de carbono, biomassa microbiana, agregação e micorriza em solos de Cerrado com diferentes usos. Ci. Agrotec., 23:617-625, 1999.

ANDERSON, J.P.E. Soil respiration. In: PAGE, A.L.; MILLER, R.H. \& KEENEY, D.R., eds. Methods of soil analysis: Chemical and microbiological properties. 2.ed. Madison, Soil Science Society of America/American Society of Agronomy, 1982. Part 2. p.831-845.

ANDERSON, T.H. \& DOMSCH, K.H. The metabolic quotient for $\mathrm{CO}_{2}\left(q \mathrm{CO}_{2}\right)$ as a specific activity parameter to assess the effects of environmental conditions, such as $\mathrm{pH}$, on the microbial biomass of forest soils. Soil Biol.Biochem., 25:393-395, 1993.

BLAKE, G.R. \& HARTGE, K.H. Bulk density. In: KLUTE, A., ed. Methods of soil analysis. 2.ed. Madison, American Society of Agronomy, 1986. Part 1. p.363-375.

BRASIL. Leis e Decretos, etc. Portaria no 006/92-N, de 15 de janeiro de 1992. Lista Oficial de Espécies da Flora Brasileira Ameaçadas de Extinção. Diário Oficial [da] República Federativa do Brasil, Brasília, jan. 1992.

BROOKES, P.C. The use of microbial parameters in soil pollution by heavy metals. Biol. Fert. Soils, 19:269-279, 1995.

CARNEIRO, M.A.C. Características bioquímicas do solo em duas cronosseqüências de reabilitação em áreas de mineração de bauxita. Lavras, Universidade Federal de Lavras, 2000. 166p. (Tese de Doutorado)

DORAN, J.W.; SARRANTONIO, M. \& LIEBIG, M.A. Soil health and sustainability. Adv. Agron., 56:1-54, 1996.

EMPRESA BRASILEIRA DE PESQUISA AGROPECUÁRIA EMBRAPA. Centro Nacional de Pesquisa do Solo. Manual de métodos e análise de solo. 2. ed. Rio de Janeiro, 1997.

EVERITT, B.S. Cluster analysis. New York, J. Wiley, 1993. $170 \mathrm{p}$.

FERNANDES, S.A. \& CARDOSO, E.J.B.N. Avaliação da biomassa microbiana e atividade de desidrogenase em diferentes sistemas de manejo do solo. In: CONGRESSO BRASILEIRO DE CIÊNCIA DO SOLO, 25., Viçosa, MG, 1995. Anais. Viçosa, MG, Sociedade Brasileira de Ciência do Solo, 1995. p.490-491.

FERREIRA, A.S.; CAMARGO, F.A.O. \& VIDOR, C. Utilização de microondas na avaliação da biomassa microbiana do solo. R. Bras.Ci. Solo, 23:991-996, 1999.

HABTE, M. Impact of simulated erosive on the abundance and activity of indigenous vesicular-arbuscular mycorrhizal endophytes in Oxisol. Biol. Fert. Soils, 7:164$167,1989$.
MAIOR, D.S. Rio protege espécies ameaçadas. Jornal do Brasil, Rio de Janeiro, 28 maio 1997. Cidade, p.18, c.1-5.

MARCHIORI JÚNIOR, M. \& MELO, W.J. Carbono, Carbono da biomassa microbiana e atividade enzimática em um solo sob mata natural, pastagem e cultura do algodoeiro. R. Bras. Ci. Solo, 23:257-263, 1999.

McCUNE, B. \& MEFFORD, M.J. Multivariate analysis of ecological data. Version 3.12. Gleneden Beach, MjM Software, 1997.

MELLONI, R. Densidade e diversidade de bactérias diazotróficas e fungos micorrízicos arbusculares em solos de mineração de bauxita. Lavras, Universidade Federal de Lavras, 2001. 173p. (Tese de Doutorado)

MELLONI, R.; MOREIRA, F.M.S.; NÓBREGA, R.S.A. \& SIQUEIRA, J.O. Eficiência e diversidade fenotípica de bactérias diazotróficas que nodulam caupi (Vigna unguiculata L. Walp) e feijoeiro (Phaseolus vulgaris L.) em solos de mineração de bauxita em reabilitação. R. Bras. Ci. Solo, 30:235-246, 2006.

MELLONI, R.; SIQUEIRA, J.O. \& MOREIRA, F.M.S. Fungos micorrízicos arbusculares em solos de área de mineração de bauxita em reabilitação. Pesq. Agropec. Bras., 38:267276,2003

SALTON, J.C.; MIELNICZUK, J.; BAYER, C.; BOENI, M.; CONCEIÇÃO, P.C.; FABRICIO, A.C.; MACEDO, M.C.M. \& BROCH, D.L. Agregação e estabilidade de agregados do solo em sistemas agropecuários em Mato Grosso do Sul. R. Bras. Ci. Solo, 32:11-21, 2008.

SIKORA, L.J. \& STOTT, D.E. Soil organic carbon and nitrogen. In: DORAN, J.W. \& JONES, A.J., eds. Methods for assessing soil quality. Madison, Soil Science Society of America, 1996. p.157-168

SILVA JÚNIOR, M.C.; SCARANO, F.R. \& CARDEL, F.S. Regeneration of an Atlantic forest formation in the understorey of Eucalyptus grandis plantation in Southeastern Brazil. J. Trop. Ecol., 11:147-152, 1995.

SILVA, A.P.; TORMENA, C.A.; FIDALSKI, J. \& IMHOFF, S. Funções de pedotransferência para as curvas de retenção de água e de resistência do solo à penetração. R. Bras. Ci. Solo, 32:1-10, 2008.

SILVEIRA, R.B.; MELLONI, R. \& MELLONI, E.P.G. Atributos microbiológicos e bioquímicos como indicadores da recuperação de áreas degradadas, em Itajubá/MG. Cerne, 12:48-55, 2006.

SINGH, K. \& BANERJEE, S.P. State of soil aggregation under plantation forest and agriculture in Alluvial soil of Doon Valley. Van Vigyan, 18:31-38, 1980.

SOUZA, W.J.O. \& MELO, W.J. Matéria orgânica em um Latossolo submetido a diferentes sistemas de produção de milho. R. Bras. Ci. Solo, 27:1113-1122, 2003. 
SPARLING, G.P. Ratio of microbial biomass carbon to soil organic carbon as a sensitive indication of changes in soil organic matter. Aust. J. Soil. Res., 30:195-207, 1992.

STATISTICA. Statistic analysis. Versão 5.0. 1995.

TÓTOLA, M.R. \& CHAER, G.M. Microrganismos e processos microbiológicos como indicadores da qualidade dos solos. In: CURI, N.; MARQUES, J.J.; GUILHERME, L.R.G.; LIMA, J.M.; LOPES, A.S.S. \& ALVAREZ V., V.H., eds. Tópicos em ciência do solo. Viçosa, MG, Sociedade Brasileira de Ciência do Solo, 2002. v.2. p.195-276. van den BERG, E. Estudo florístico e fitossociológico de uma floresta ripária em Itutinga, MG, e análise das correlações entre variáveis ambientais e a distribuição das espécies de porte arbóreo-arbustivo. Lavras, Universidade Federal de Lavras, 1995. 73p. (Tese de Mestrado)

ZONTA, E.P.; MACHADO, A.A. \& SILVEIRA JÚNIOR, P. Sistemas de análise estatística para microcomputadores (SANEST). Pelotas, Universidade Federal de Pelotas, 1984. 151p. 